\title{
Rotational thromboelastometry for perioperative blood conservation? It is all in the bloody details
}

\author{
Rodolfo V. Rocha, MD, Derrick Y. Tam, MD, and Stephen E. Fremes, MD, MSc
}

\footnotetext{
From the Division of Cardiac Surgery, Schulich Heart Centre, Department of Surgery, Sunnybrook Health Sciences Centre, University of Toronto, Toronto, Ontario, Canada.

Disclosures: Authors have nothing to disclose with regard to commercial support.

Received for publication July 26, 2018; accepted for publication July 27, 2018; available ahead of print Sept 1, 2018.

Address for reprints: Stephen E. Fremes, MD, MSc, FRCSC, Schulich Heart Centre, Sunnybrook Health Sciences Centre, 2075 Bayview Ave, Rm H4 05, Toronto, Ontario, Canada M4N 3M5 (E-mail: stephen.fremes@ sunnybrook.ca).

J Thorac Cardiovasc Surg 2019;157:1055-7

$0022-5223 / \$ 36.00$

Copyright (c) 2018 by The American Association for Thoracic Surgery

https://doi.org/10.1016/j.jtcvs.2018.07.080
}

Blood transfusion is associated with various complications, but is also likely an independent risk factor of mortality following cardiac surgery. Long-term risk-adjusted mortality has been consistently associated with transfusion. Engoren and colleagues ${ }^{1,2}$ reported a 5-year mortality risk ratio of 1.7 (95\% confidence interval [CI], 1.4-2.0). Likewise, von Heymann and colleagues ${ }^{3}$ associated transfusion with a mortality hazard ratio of 1.340 (95\% CI, 1.109-1.620) and Koch and colleagues ${ }^{4}$ observed an association of transfusion with a risk-adjusted reduction in survival (0.074 $\pm 0.016 ; P<.0001)$. Furthermore, the production cost of a unit of packed red blood cells (RBCs) is high, about CAN\$450 in Ontario, ${ }^{5}$ with the true cost of RBC transfusion in the United States ranging from \$522 to $\$ 1183$ after the incorporation of administration, labor, material, and overhead costs. ${ }^{6}$ On the other hand, transfusion can be a life-saving therapeutic measure, especially during procedures associated with major blood loss and coagulopathy, such as aortic surgery.

Several isolated strategies have been previously examined. Intraoperative topical hemostatic agents have been showed to reduce blood transfusion from $47.1 \%$ to $29.2 \%(P<.01){ }^{7}$ Antifibrinolytic agents, such as epsilonaminocaproic or tranexamic acid, have been associated with a reduction in transfusions. ${ }^{8-10}$ Use of cell savers have also been associated with a decrease in blood transfusions (relative risk, $0.77 ; 95 \% \mathrm{CI}, 0.69-0.86)^{11}$ as has a restrictive strategy of postoperative red cell transfusion (odds ratio, 0.41; 95\% CI, 0.37-0.47). ${ }^{12}$ Ad and colleagues $^{13}$ described a reduction in blood products transfused from $54 \%$ to $25 \%$ following propensity score matching, with no difference in outcomes, using a multidisciplinary approach involving multiple strategies (ie, widespread use of cell salvage, acute normovolemic hemodilution, retrograde autologous priming, and intraand postoperative restrictive red cell transfusion) to decrease transfusions. Nevertheless, the rate of blood

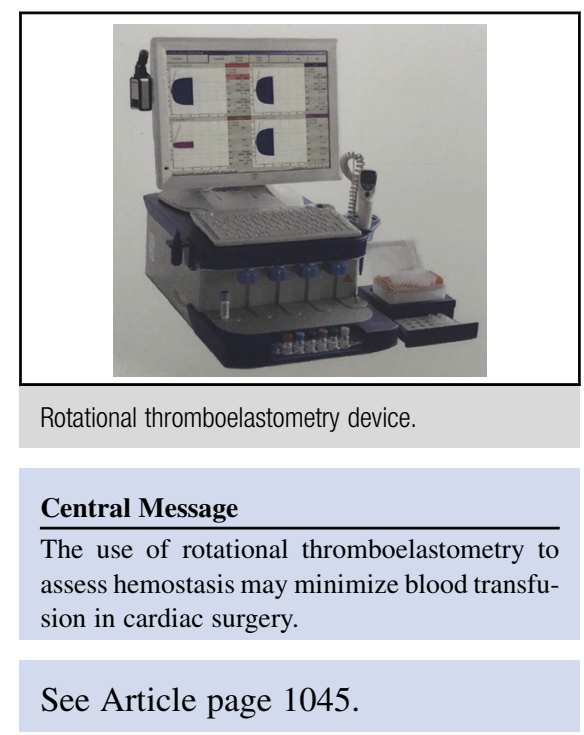

product transfusion after cardiac surgery varies substantially amongst institutions. The risk-adjusted rates of blood transfusion during coronary artery bypass grafting ranges from $18.1 \%$ to $68.1 \%$ in Ontario. ${ }^{14}$ Thus, strategies to reduce blood transfusions and variability in transfusion remain relevant to contemporary cardiac surgery. Recently, a point-of-care assessment for hemostasis using rotational thromboelastometry (ROTEM) has emerged as an adjunct to better determine the need for blood transfusion intraoperatively. ${ }^{15}$

ROTEM relies on viscoelastic principles to assess hemostasis in whole blood, through the use of multiple tests: INTEM, which activates the contact phase of hemostasis, evaluates the intrinsic coagulation pathway; EXTEM activates hemostasis via physiologic activator tissue factor, being a screening test for extrinsic coagulation pathway abnormalities; HEPTEM, performed in the presence of heparinase, detects residual heparin; and FIBTEM, which is an assay to evaluate the fibrin part of the clot. The use of ROTEM has been associated with a reduction in the proportion of patients transfused with RBCs (relative risk, 0.86; 95\% CI, 0.79-0.94) in a recent meta-analysis involving mostly cardiac surgery patients. ${ }^{16}$

St Onge and colleagues ${ }^{17}$ report their single-center experience in using ROTEM during aortic surgery and compare their results with aortic cases performed without ROTEM. The primary objective was to assess the influence of a point-of-care ROTEM-based algorithm in aortic surgery, 
an operative group typically with high blood transfusion requirements. The primary outcome was RBC transfusion. Two different propensity-score matching models were used, yielding slightly different conclusions. In the primary analysis, using a parsimonious propensity score model, there was a trend toward reducing RBC transfusion in the ROTEM group (58\% vs $47 \% ; P=.08)$, which was also associated with transfusion of fewer units of RBCs (median, 1.0 units; interquartile range [IQR], 0.0-4.0 units vs median, 0.0 units; IQR, $0.0-2.0$ units; $P=.03$ ), fresh frozen plasma (median, 0.0 units; IQR, 0.0-4.0 units vs mean, 0.0 units; IQR, 0.0-2.0 units; $P=.04$ ), and a decrease in recombinant factor VII $(11 \%$ vs $4 \% ; P=.04)$, whereas desmopressin use was increased $(6 \%$ vs $16 \% ; P=.02)$. There was no difference in perioperative mortality $(4 \%$ vs $3 \% ; P=.99)$ or re-exploration for bleeding $(12 \%$ vs $10 \% ; P=.68)$, whereas massive transfusion was reduced $(21 \%$ vs $11 \%$; $P=.04)$.

However, in a sensitivity analysis using a semisaturated propensity score and including all preoperative variables, none of the transfusion results were statistically different between the control and ROTEM cohorts, although directionally similar to the findings using the parsimonious match. Recombinant factor VII was identical in the 2 groups. Desmopressin use was increased in the ROTEM patients $(5 \%$ vs $18 \% ; P<.01)$ and a trend toward more prothrombin complex concentrate requirement was observed when using ROTEM (5\% vs $11 \% ; P=.07)$. Again we saw no differences in death or re-exploration, but in these patients massive transfusion was no different as well $(13 \%$ vs $15 \% ; P=.67)$.

The conflicting results between the primary and sensitivity analyses suggest that the study findings are not robust; the findings are suggestive rather than definitive regarding the benefits of ROTEM in this population. The study compared the experimental group (ie, ROTEM use) with historical controls; the before-after study design can be associated with temporal biases, despite propensity score matching. A large proportion of the ROTEM population was lost after adjustment in both the initial (40\% [from 188 to 112]) and the latter analysis (49\% [from 188 to 95]). This suggests that there may be important confounders even within the relatively short period of 3 years. In addition, there were several variables after propensity score matching with standardized mean differences $>10 \%$. Moreover, the retrospective nature of the study cannot adjust for unmeasured confounders, which only a randomized controlled trial can address. ${ }^{18}$

St Onge and colleagues ${ }^{17}$ must be congratulated for their important contribution. Their implementation of the pointof-care ROTEM hemostasis assessment in a patient group at increased risk of bleeding and transfusion is notable. It is also important to emphasize that successful blood conservation requires a multidisciplinary approach, as recommended by the Society of Thoracic Surgeons blood conservation clinical practice guidelines. ${ }^{19}$ Successful multidisciplinary patient blood management programs have provided improved results in Australia and Canada. ${ }^{20,21}$ These programs involve pre-, peri-, and postoperative measurements to safely reduce transfusion, integrating and educating patients, family physicians, cardiologists, surgeons, anesthesiologists, intensivists, hematologists, nurses, and nutritionists.

This study demonstrates the safety of ROTEM in aortic surgery, but also leads us to focus on stricter adoption of evidence-based protocols and guidelines by physicians, as well as to understand that blood transfusion should be addressed in a multidisciplinary fashion, integrating different health care professionals and addressing both prevention and treatment.

\section{References}

1. Engoren MC, Habib RH, Zacharias A, Schwann TA, Riordan CJ, Durham SJ. Effect of blood transfusion on long-term survival after cardiac operation. Ann Thorac Surg. 2002;74:1180-6.

2. Engoren M, Habib RH, Hadaway J, Zacharias A, Schwann TA, Riordan CJ, et al. The effect on long-term survival of erythrocyte transfusion given for cardiac valve operations. Ann Thorac Surg. 2010;90:760-6.

3. von Heymann C, Kaufner L, Sander M, Spies C, Schmidt K, Gombotz H, et al. Does the severity of preoperative anemia or blood transfusion have a stronger impact on long-term survival after cardiac surgery? J Thorac Cardiovasc Surg. 2016;152:1412-20.

4. Koch CG, Li L, Duncan AI, Mihaljevic T, Loop FD, Starr NJ, et al. Transfusion in coronary artery bypass grafting is associated with reduced long-term survival. Ann Thorac Surg. 2006;81:1650-7.

5. Amin M, Fergusson D, Wilson K, Tinmouth A, Aziz A, Coyle D, et al. The societal unit cost of allogenic red blood cells and red blood cell transfusion in Canada. Transfusion. 2004;44:1479-86.

6. Shander A, Hofmann A, Ozawa S, Theusinger OM, Gombotz H, Spahn DR. Activity-based costs of blood transfusions in surgical patients at four hospitals. Transfusion. 2010;50:753-65.

7. Nasso G, Piancone F, Bonifazi R, Romano V, Visicchio G, De Filippo CM, et al. Prospective, randomized clinical trial of the FloSeal matrix sealant in cardiac surgery. Ann Thorac Surg. 2009;88:1520-6.

8. Munoz JJ, Birkmeyer NJ, Birkmeyer JD, O’Connor GT, Dacey LJ. Is epsilonaminocaproic acid as effective as aprotinin in reducing bleeding with cardiac surgery? A meta-analysis. Circulation. 1999;99:81.

9. Lu J, Meng H, Meng Z, Sun Y, Pribis JP, Zhu C, et al. Epsilon aminocaproic acid reduces blood transfusion and improves the coagulation test after pediatric openheart surgery: a meta-analysis of 5 clinical trials. Int J Clin Exp Pathol. 2015;8: 7978-87.

10. Hébert PC, Fergusson DA, Hutton B, Mazer CD, Fremes S, Blajchman M, et al. Regulatory decisions pertaining to aprotinin may be putting patients at risk. Can Med Assoc J. 2014;186:1379-86.

11. Carless PA, Henry DA, Moxey AJ, O'Connell D, Brown T, Fergusson DA. Cell salvage for minimising perioperative allogeneic blood transfusion. Cochrane Database Syst Rev. 2010;CD001888.

12. Mazer CD, Whitlock RP, Fergusson DA, Hall J, Belley-Cote E, Connolly K, et al. Restrictive or liberal red-cell transfusion for cardiac surgery. N Engl J Med. 2017; 377:2133-44.

13. Ad N, Holmes SD, Patel J, Shuman DJ, Massimiano PS, Choi E, et al. The impact of a multidisciplinary blood conservation protocol on patient outcomes and cost after cardiac surgery. J Thorac Cardiovasc Surg. 2017;153:597-605.

14. ICES Report on Coronary Artery Bypass Surgery in Ontario_final. Available at: https://www.ices.on.ca/flip-publication/report-on-coronary-artery-bypass-surgeryin-ontario/files/assets/basic-html/page6.html. Accessed July 20, 2018.

15. Ogawa S, Szlam F, Chen EP, Nishimura T, Kim H, Roback JD, et al. A comparative evaluation of rotation thromboelastometry and standard coagulation tests in hemodilution-induced coagulation changes after cardiac surgery. Transfusion. 2012;52:14-22. 
16. Wikkelsø A, Wetterslev J, Møller AM, Afshari A. Thromboelastography (TEG) or rotational thromboelastometry (ROTEM) to monitor haemostatic treatment in bleeding patients: a systematic review with meta-analysis and trial sequential analysis. Anaesthesia. 2017;72:519-31.

17. St Onge S, Lemoine E, Bouhout I, Rochon A, El-Hamamsy I, Lamarche Y, et al. Evaluation of the real-world impact of rotational thromboelastometry-guided transfusion protocol in patients undergoing proximal aortic surgery. $J$ Thorac Cardiovasc Surg. 2019;157:1045-54.

18. Gaudino M, Di Franco A, Rahouma M, Tam DY, Iannaccone M, Deb S, et al. Unmeasured confounders in observational studies comparing bilateral versus single internal thoracic artery for coronary artery bypass grafting: a meta-analysis. J Am Heart Assoc. 2018;7(1). pii: e008010.
19. Society of Thoracic Surgeons Blood Conservation Guideline Task Force Ferraris VA, Brown JR, Despotis GJ, Hammon JW, Reece TB, Saha SP, et al 2011 update to the Society of Thoracic Surgeons and the Society of Cardiovascular Anesthesiologists blood conservation clinical practice guidelines. Ann Thorac Surg. 2011;91:944-82.

20. Leahy MF, Hofmann A, Towler S, Trentino KM, Burrows SA, Swain SG, et al. Improved outcomes and reduced costs associated with a health-system-wide patient blood management program: a retrospective observational study in four major adult tertiary-care hospitals. Transfusion. 2017;57:1347-58.

21. Freedman J, Luke K, Escobar M, Vernich L, Chiavetta JA. Experience of a network of transfusion coordinators for blood conservation (Ontario Transfusion Coordinators [ONTraC]). Transfusion. 2008;48:237-50. 